\title{
A Clinicopathological Study on the Electrical Axis of the Heart in 1,000 Autopsy Cases
}

\author{
Masaya Sugiura, M.D., Shinichiro Ohkawa, M.D., \\ Keisuke Hiraoka, M.D., Iwao Kuwajima, M.D., \\ and Keiji UEDA, M.D.
}

\section{SUMMARY}

The elestrical axis of the heart in 1,000 aged people more than 56 years of age was classified as normal axis in 58\%, left axis deviation in $17.4 \%$, mild left axis deviation in $21.9 \%$, and right axis deviation in $2.7 \%$.

Pathological examination disclosed that left axis deviation was associated with myocardial infarction in $20 \%$, right bundle branch block in $16 \%$, but showed no significant relationships with coronary sclerosis, myocardial fibrosis and cardiac hypertrophy. Right axis deviation was associated with right bundle branch block in $66.7 \%$ and right ventricular hypertrophy in $22.2 \%$.

\section{Additional Indexing Words :}

Left axis deviation Right axis deviation Conduction disturbance Conduction system Myocardial infarction Right bundle branch block

7 HE shift of electrical axis of the heart toward the left, ${ }^{1,2)}$ and the in1 creased incidence of left axis deviation (LAD) ${ }^{3-7)}$ have been repeatedly confirmed in the aged, but its pathogenesis has yet to be established. In 1956, Grant $^{8}$ ' showed that the LAD was anterior fascicular block due to coronary heart discase, such as myocardial infarction and fibrosis. Recently various chronic conduction disturbances, such as atrioventricular block, and bundle branch block, could be explained by unknown degenerative changes rather than myocardial infarction. ${ }^{9-13)}$ The purpose of this report is to clarify the pathogenesis of axis deviation of the aged by clinicopathological correlation study in 1,000 autopsy cases.

\section{Materials and Methods}

A total of 1,000 aged cases of consecutive autopsy was the subject, in whom the morphological abnormalities of the cardiovascular system were reported in Tokyo.

From the Department of Internal Medicine, Tokyo Metropolitan Geriatric Hospital (Yoiku-in),

Received for publication April 18, 1975. 
detail elsewhere. ${ }^{14)}$ There were 433 men and 567 women, with ages ranging from 56 to 99 years. Electrical axis was determined by triaxial method. Normal axis (NAD) was defined as from $0^{\circ}$ to $+89^{\circ}$, mild left axis deviation ( $\left.L^{\prime} A D\right) 0^{\circ}$ to $-29^{\circ}$, left axis deviation (LAD) $-30^{\circ}$ to $-180^{\circ}$, and right axis deviation (RAD) $+90^{\circ}$ to $+180^{\circ}$. There were often cases showing progressive changes of the electrical axis, in whom the axis in later period was selected as representative one. Blood pressure was checked at 3 periods; that is the time of entrance to the home for the aged, time of admission to the hospital, and 1 year prior to death. Cases always showing the blood pressure more than $170 / 90 \mathrm{mmHg}$ were defined as steady hypertension; and cases whose blood pressure was on occasion higher or lower than that value were labile hypertension. ${ }^{15}$ ?

Pathological examination included heart weight, thickness of the ventricular wall, coronary atherosclerosis, and presence or absence of myocardial infarction and fibrosis as previously reported. ${ }^{16)}$ Cardiac hypertrophy was defined as the heart weight of more than $351 \mathrm{Gm}$ and right ventricular hypertrophy as those with the thickness of the right ventricular free wall of more than $5 \mathrm{~mm}$. Myocardial fibrosis was observed at least on one horizontal cut surface in gross and microscopic examination, and the patchy fibrosis and moderate to severe interstitial fibrosis were entered to the analysis. Coronary sclerosis was evaluated by stenotic index, as described previously. ${ }^{17)}$ The degree of coronary stenosis was classified into 5 degrees, count 5 in $100 \%$ obstruction, 4 in $75 \%, 3$ in $50 \%, 2$ in $25 \%$ stenosis, and 1 in slight sclerosis, and the stenotic index was the sum of the highest degree of stenosis from 3 main coronary arteries. Stenotic index ranged from 0 to 15 ; normal or mild stenosis in index 0 to 8, moderate stenosis in 9 to 12 , and severe stenosis in 13 and over.

\section{RESULTS}

1) Distribution of the electrical axis:

There were 580 cases of NAD (58.0\%), 219 of L'AD (21.9\%), 174 of LAD (17.4\%), and 27 of RAD (2.7\%) as shown in Fig. 1. There was no significant sex difference.

2) Aging and electrical axis:

There was a tendency of NAD to decrease and of L'AD and LAD to increase with age (Fig. 1), but these changes were statistically not significant.

3) Cardiovascular abnormalities and electrical axis (Fig. 2):

There were 343 morphologically normal hearts among 1,000 cases, ${ }^{14}$ ) from which cases of atrial fibrillation and steady hypertension were further eliminated, leaving 275 normal hearts and 725 cases of cardiovascular diseases and/or abnormalities (Fig. 2). Incidence of each electrical axis was compared in both groups, showing significantly higher incidence of NAD in normal hearts $(p<0.005)$, and LAD in cardiac cases $(p<0.01)$. Normal heart was found in 34 cases $(19.5 \%$ ) among a total of 174 cases of LAD, which were cases of so-called isolated LAD. 


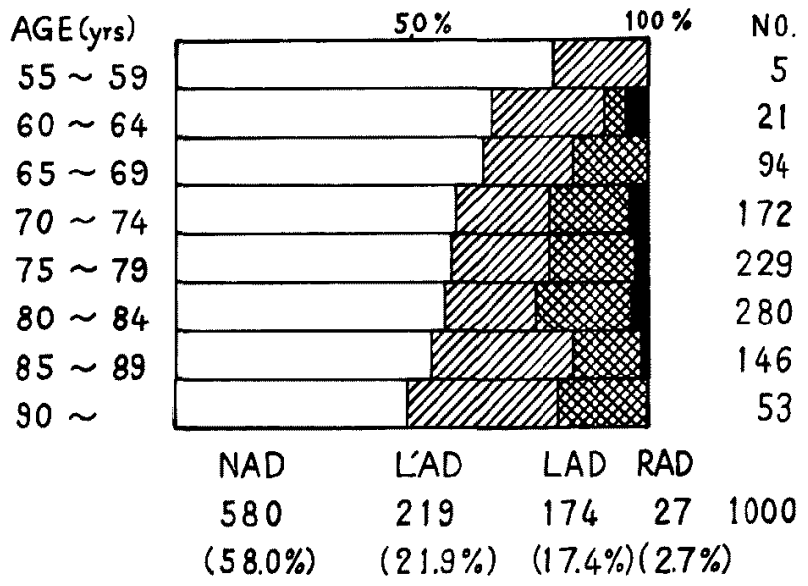

Fig. 1. Distribution of the electrical axis of the heart, and the incidence of axis deviation with age.

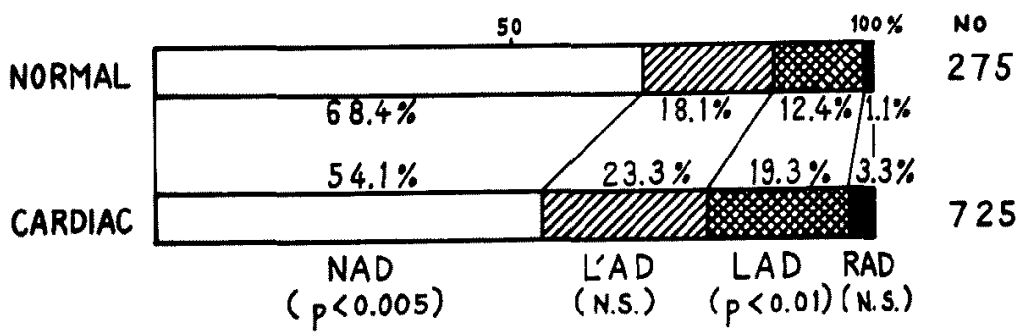

Fig. 2. Incidence of 4 groups of electrical axis in the pathologically normal and abnormal hearts.

Table I. Pathological Findings in Various Electrical Axis in the Aged

\begin{tabular}{l|r|r|r|r|r|r|r|r}
\hline Axis & Cases & RBBB & LBBB & $\begin{array}{c}\text { Coronary } \\
\text { sclerosis }\end{array}$ & $\begin{array}{c}\text { Myocardial } \\
\text { fibrosis }\end{array}$ & $\begin{array}{c}\text { Myocardial } \\
\text { infarction }\end{array}$ & LVH & RVH \\
\hline NAD & 580 & $11(1.9 \%)$ & $4(0.7 \%)$ & $234(40.3 \%)$ & $134(23.1 \%)$ & $67(11.6 \%)$ & $124(21.4 \%)$ & $22(3.8 \%)$ \\
L'AD & 219 & $9(4.1 \%)$ & $2(0.9 \%)$ & $96(43.8 \%)$ & $53(24.2 \%)$ & $31(14.2 \%)$ & $55(25.1 \%)$ & $4(1.8 \%)$ \\
LAD & $17428(16.1 \%)$ & $7(4.0 \%)$ & $87(50.0 \%)$ & $34(19.5 \%)$ & $36(20.7 \%)$ & $50(28.7 \%)$ & $7(4.0 \%)$ \\
RAD & $2718(66.7 \%)$ & 0 & $12(44.4 \%)$ & $4(14.8 \%)$ & $3(11.1 \%)$ & $4(14.8 \%)$ & $6(22.2 \%)$ \\
Total & $1,00066(6.6 \%)$ & $13(1.3 \%)$ & $429(42.9 \%)$ & $225(22.5 \%)$ & $137(13.7 \%)$ & $233(23.3 \%)$ & $39(3.9 \%)$ \\
& p $<0.005$ & p<.010 & N.S. & N.S. & p<0.05 & N. S. & p<0.005
\end{tabular}

4) Electrical axis and bundle branch block (Table I):

Right bundle branch block (RBBB) was associated in 18 cases $(66.7 \%$ ) out of 27 cases of RAD, and in 28 cases (16.1\%) out of 174 of LAD. The incidence of $\mathrm{RBBB}$ in these 2 groups were significantly higher than those in other groups. Incidence of left bundle branch block (LBBB) was the highest 
in group of LAD (4\%), which was statistically significant.

5) Electrical axis and coronary sclerosis (Table I):

The incidence of moderate to severe coronary sclerosis (stenotic index more than 9) was not significantly different among 4 groups.

6) Electrical axis and myocardial fibrosis and infarction (Table I):

The incidence of myocardial fibrosis was not significantly different, but myocardial infarction was frequent in cases of LAD (20.7\%), which was statistically significant $(\mathrm{p}<0.05)$. Among cases of myocardial infarction, massive large infarction and anterior infarction were frequent in LAD, but the difference was statistically not significant.

7) Electrical axis and cardiac hypertrophy (Table I):

The incidence of cardiac hypertrophy was not significant by the electrical axis, but right ventricular hypertrophy was higher (22\%) in the RAD group than other groups $(\mathrm{p}<0.005)$.

\section{Discussion}

The incidence of LAD depends on age of the study groups; $0.8 \%{ }^{2)}$ to $5.3 \%$ in younger age, and $4.8 \%$ to $\left.\left.19.5 \% \%^{4}, 6\right)-81,19\right), 20$ in the older age groups. The incidence in this report $(17.4 \%)$ was almost similar to the value (15\%) among 2,189 living aged people reported previously." Increase of LAD with aging in this report was not statistically significant, probably due to large number in the 8th and 9th decades compared to the other age groups.

The incidence of LAD has been reported to be higher in diseased hearts, $\left.{ }^{18}\right)$ which we could confirm in this report. A total of 725 cases of diseased heart consisted of 428 cases of coronary sclerosis including 137 cases of myocardial infarction, 237 cases of cardiac hypertrophy, 120 cases of valvular diseases, 96 cases of conduction disturbances, and so on. ${ }^{14}$ ) LAD was found in 19.3\% among this group, on the other hand LAD was also found in $12.4 \%$ in normal heart group, and the latter was the so-called isolated LAD. ${ }^{5}$ ) This fact indicated that LAD could not be induced by diseases only. Blackburn et $\mathrm{al}^{2}$ ) examined the incidence of LAD in 3 countries, where the incidence of coronary heart disease was markedly different. Their results showed there was the same tendency of LAD to increase along aging.

Association of axis deviation among a total of 177 cases of RBBB showed that LAD was the highest incidence $(52 \%)$, followed by NAD $(24.8 \%)$ and RAD $(23.2 \%)$ in the aged. ${ }^{21)}$ There was, however, few studies on the incidence of bundle branch block in various groups of electrical axis as shown in this study. There were 174 cases of LAD, among which 28 cases $(16 \%)$ 
Table II. Pathological Studies on the Left Axis Deviation

\begin{tabular}{|c|c|c|c|c|c|c|c|c|}
\hline Year & Author & $\begin{array}{l}\text { Total } \\
\text { cases }\end{array}$ & Age & $\begin{array}{l}\text { Cases of } \\
\text { LAD }\end{array}$ & $\begin{array}{c}\text { Myocardial } \\
\text { fibrosis }\end{array}$ & $\begin{array}{l}\text { Myocardial } \\
\text { infarction }\end{array}$ & LVH & Isolated \\
\hline 1956 & Grant $^{8)}$ & 672 & $31-$ & $131(19.5 \%)$ & $\zeta$ & $54(41.2 \%)$ & $35(26.7 \%)$ & $23(17.5 \%)$ \\
\hline 1961 & Curd $^{19)}$ & 2,500 & $40-$ & $252(10.1 \%)$ & & & & \\
\hline & & & & $154 *$ & I & $80(52.0 \%)$ & $\gamma$ & $4(2.5 \%)$ \\
\hline 1965 & Corne ${ }^{20)}$ & 96 & Y & 23 & $21(91.3 \%)$ & $6(26.0 \%)$ & $22(95.6 \%)$ & \\
\hline 1965 & Castle ${ }^{23)}$ & 2,500 & adult & $\begin{array}{l}105(4.2 \%) \\
55^{*}\end{array}$ & $14(25.4 \%)$ & $12(21.8 \%)$ & $18(32.7 \%)$ & $11(20.0 \%)$ \\
\hline 1966 & Pryor 24) & ノ & $5-$ & 28 & $24(85.7 \%)$ & $3(10.7 \%)$ & I & \\
\hline 1967 & Entman ${ }^{253}$ & 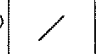 & $\gamma$ & 15 & $\gamma$ & $12(80.0 \%)$ & $9(60.0 \%)$ & \\
\hline 1969 & Bahl $^{26)}$ & Y & $19-94$ & 353 & $162(46.0 \%)$ & $137(38.8 \%)$ & Y & $13(3.6 \%)$ \\
\hline 1975 & Sugiura & 1,000 & 56-99| & $174(17.4 \%)$ & $34(19.5 \%)$ & $36(20.7 \%)$ & $50(28.7 \%)$ & $34(19.5 \%)$ \\
\hline
\end{tabular}

were associated with RBBB. This fact could be explained by the anatomical relationships of right bundle branch and left anterior fascicles as the terminal region of the branching portion of the bundle of His.

Out of 27 cascs of $\mathrm{RAD}$, about $67 \%$ was associated with the RBBB. Though the real number of RAD (27 cases) was less than LAD (174 cases), high incidence of association of RAD with RBBB was a remarkable fact. Left posterior fascicles were larger and more extensive than the anterior ones, and RAD could not be induced easily. But once RAD was produced, there could be expected an extensive lesions, inducing LBBB or RBBB with RAD. ${ }^{22}$ )

Pathological studies on the genesis of LAD have been performed by several authors $\left.\left.{ }^{19}, 20\right), 23\right)-27$ ) after the study of Grant ${ }^{8 /}$ (Table II). Most of these studies suggested importance of coronary heart disease. However, some of these studies did not treat serial cases (preselection of cases), ${ }^{19), 201,23)}$ were lacking control group, ${ }^{19,23)-26)}$ and had not enough size of materials. ${ }^{20,24), 25)}$ Our analysis in this report was characterized by (1) the comparison between groups of various electrical axis, (2) examination of coronary sclerosis as a base of myocardial ischemic lesions, and (3) consecutive autopsy cases.

As a result of it, no evidences were obtained indicating higher incidence of coronary sclerosis, cardiac hypertrophy and myocardial fibrosis. On the other hand, myocardial infarction occurred with a significantly higher rate in cases of LAD. Incidence of myocardial fibrosis, which was emphasized by $\mathrm{Grant}^{8}$ ) was not described in his original paper. Genesis of LAD could be concluded to be related to a large myocardial necrosis such as infarction in about $20 \%$ of cases, and most of LAD had no influence of ischemia.

These facts corresponded well to the pathologic findings in the most cases of various conduction disturbances. ${ }^{91-13)}$ Among a total of 34 cases 
including AV block (8), complete LBBB (8), RBBB (18), only 4 cases could be explained by acute myocardial infarction and other 28 cases $(82 \%)$ showed no definite relations to the coronary sclerosis, myocardial fibrosis nor cardiac hypertrophy. ${ }^{13}$ ) Grant's hypothesis on the genesis of LAD was the left ventricular parietal block due to myocardial ischemic lesions. But lesions of left bundle branch were mainly found in the branching portion of the AV bundle or the proximal portion of the left bundle branch in complete $L B B B,{ }^{25)} \mathrm{RBBB}$ with $\mathrm{LAD},{ }^{12}$ ) and $\mathrm{RBBB}$ with $\mathrm{RAD}{ }^{22}$ ) Thus the main region of fascicular block of the left bundle branch could be the septal summit, which was not the portion of usual pathological examination. Pathological study on the LAD necessarily leads to the histological examination of the conduction system, which should be the problem in future.

\section{REFERENCES}

1. Simonson E: Differentiation between normal and abnormal in electrocardiography. The CV Mosby Co, St Louis, 1961

2. Blackburn H, Vasquez CL, Keys A: The aging electrocardiogram. A common aging process or latent coronary artery disease? Am J Cardiol 20:618, 1967

3. Hiss RG, Lamb LE, Allen MF: Electrocardiographic findings in 67,375 asymptomatic subjects. Normal values. Am J Cardiol 6: 200, 1960

4. Sugiura M, Okada R, lizuka T, Kubo F, Hiraoka K, Ohkawa S: A consideration on the left axis deviation, with special reference to the right bundle branch block associated with left axis deviation as a bilateral bundle branch block. Saishin Igaku 23: 1460, 1968

5. Ostrander LD: Left axis deviation. Prevalence, associated conditions and prognosis. An epidemiologic study. Ann Int Med 75: 23, 1971

6. Ozawa T, Iwamoto M, Handa N, Kishimoto A, Su S, Nagakawa Y, Tominaga M, Yoshikawa M: Electrocardiographic abnormalities associated with advancing age. Jap J Geriatr 10: 50, 1973

7. Mihalick MJ, Fisch D: Electrocardiographic findings in the aged. Am Heart J 87: 117, 1974

8. Grant RP: "Left axis deviation: an clectrocardiographic pathologic correlation study". Circulation 14: 233, 1956

9. Lenègre J: Contribution á l'étude des blocs de branche. J-B Bailliere et fils, Paris, 1958

10. Lev M: The anatomic basis for disturbances in conduction and cardiac arrhythmias. Prog Cardiovasc Dis 2: 360, 1960

11. Davies MJ: Pathology of conducting tissue of the heart, Butterworths, London, 1971

12. Sugiura $M$, Okada $R$, Hiraoka $K$, Ohkawa $S$ : Histological studies on the conduction system in 14 cases of right bundle branch block associated with left axis deviation. Jap Heart J 10: 121,1969

13. Sugiura M, Ohkawa S, Okada R: Aging of the central fibrous body with a special reference to conduction disturbance. Proc 8th Intern Congr Gerontol 2: 23, 1969

14. Sugiura M, Hiraoka $\mathrm{K}$, Onkawa S, Shimada H: A clinicopathological study on the heart diseases in the aged. The morphological classification of the 1,000 consecutive autopsy cases. Jap Heart J 16: 526, 1975

15. Hiraoka $\mathrm{K}$, Shimada $H$, Okada $R$, Sugiura $M$ : A clinicopathological study on relationship of the focal hyperplasia of adrenal cortex to hypertension and arteriosclerosis in the aged. Jap Heart J 12: 450, 1971

16. Sugiura M, Okada R, Iizuka H, Iizuka T, Hiraoka K, Ohkawa S, Shimada H: Clinicopatho- 
logical studies on normality in the aged heart. Jap J Geriatr 6: 297, 1969

17. Sugiura M, Okada R: A clinicopathological study on the natural history of myocardial infarction in the aged. Jap Circulat J 36: 1, 1972

18. Gorman PA, Calatayud JB, Abraham S, Caceres CA: Effects of age and heart disease on the QRS axis during the seventh through the tenth decades. Am Heart J 67: 39, 1964

19. Curd GW, Jr, Hicks WM, Jr, Gyorkey F: Marked left axis deviation. Indication of cardiac abnormality. Am Heart J 62: 462, 1961

20. Corne RA, Parkin TW, Brandenburg RO, Brown AL, Jr: Significance of marked left axis deviation. Electrocardiographic-pathologic correlative study. Am J Cardiol 15: 605, 1965

21. Sugiura M, Hiraoka K, Ohkawa S: An electrocardiographic study on the electrical axis of right bundle branch block in the aged. Jap Heart J 14:510, 1973

22. Sugiura M, Hiraoka $\mathbf{K}$, Ohkawa S: A histological study on the conduction system in 16 cases of right bundle branch block associated with right axis deviation. Jap Heart J 15: 113, 1974

23. Castle CH, Keane WM: Electrocardiographic "pcriinfarction block". $\Lambda$ clinical and pathologic correlation. Circulation 31: 403, 1965

24. Pryor R, Blount SG Jr: The clinical significance of true left axis deviation. Left intraventricular blocks. Am Heart J 72: 391, 1966

25. Entman ML, Estes EH Jr, Hackel DB: The pathologic basis of the electrocardiographic patterns of parietal block. Am Heart J 74: 202, 1967

26. Bahl OP, Walsh TJ, Massie E: Left axis deviation. An electrocardiographic study with postmortem correlation. Brit Heart J 31: 451, 1969

27. Sugiura M, Okada R, Ohkawa S, Shimada H: Pathohistological studies on the conduction system in 8 cases of complete left bundle branch block. Jap Heart J 11: 5, 1970 